\title{
Prevalence of Tuberculosis in Cattle and Buffalo at Various Livestock Farms in Punjab
}

\author{
Manzoor Ahmed Ghumman ${ }^{1}$, Abdul Whab Manzoor ${ }^{1}$, Sarwat $\mathrm{Naz}^{1}$, \\ Rais Ahmad ${ }^{2}$ and Rasheed Ahmad ${ }^{1}$ \\ ${ }^{1}$ Veterinary Research Institute, ZarrarShaheed Road, Lahore Cantt, Pakistan \\ ${ }^{2}$ Institute of Microbiology, University of Agriculture, Faisalabad, Pakistan
}

Correspondence should be addressed to: Abdul Whab Manzoor; abdul797@yahoo.com

Received 13 January 2013; Accepted 23 January 2013; Published 14 March 2013

Academic Editor: Bryce M. Buddle

Copyright (C) 2013 Manzoor Ahmed Ghumman, Abdul Whab Manzoor, Sarwat Naz, Rais Ahmad and Rasheed Ahmad. Distributed under Creative Commons CC-BY 3.0

\begin{abstract}
Tuberculosis is an infectious diseases of animals which causes heavy economic losses in livestock. A total of 17601 animals including 9021cattle and 8580 buffalo were screened for tuberculosis at five government and fifty private livestock farms in Punjab, Pakistan from 2006 to 2010. Out of these, 1057 (11.71\%) cattle and 1027(11.96\%) buffalo were found to be positive for tuberculosis in intradermal tuberculin test while 499 (5.53\%) cattle and $567(6.62 \%)$ buffalo were found suspected for tuberculosis. Statistical analysis showed insignificant difference in both species for prevalence of TB.
\end{abstract}

Keywords: Prevalence, Tuberculosis, Cattle, Buffalo, Livestock Farms.

\section{Introduction}

Tuberculosis (TB) is an infectious disease caused by pathogenic acid fast organism Mycobacterium bovis (M. Bovis) which affects cattle, buffalo and other domesticated animals and wildlife species. TB is characterized by formation of nodular granulomas known as tubercles. TB in cattle involves the lungs and it spreads from animal to animal through aerosol transmition. M.bovis is a zoonotic bacteria and is the major cause of human infection in underdeveloped countries (Daborn, 1995). Milk is the principle vector of transmission of $M$. bovis from animals to human (Collier et al., 1998). Bovine TB due to M.bovis is a major cause of human gastrointestinal tuberculosis in developing countries where bovine milk is often not pasteurized before use (Bonsu, 2000).

TB is a disease which is considered to be of socio-economic or public health importance

Cite this Article as: Manzoor Ahmed Ghumman, Abdul Whab Manzoor, Sarwat Naz, Rais Ahmad and Rasheed Ahmad (2013), "Prevalence of Tuberculosis in Cattle and Buffalo at Various Livestock Farms in Punjab," International Journal of Veterinary Medicine: Research \& Reports, Vol. 2013 (2013), Article ID 145084, DOI: $10.5171 / 2013.145084$ 
and has great significance in the international trade of animals and animal products (Cousins, 2001). TB causes heavy economic losses through poor carcass, low quality hides and skin, reduced milk production, reduced productivity and lowered working capacity.

The present study was conducted to investigate the prevalence of TB in buffalo and cattle at various livestock farms in Pakistan.

\section{Material and Method}

17601 animals at five government and fifty private livestock farms in Pakistan were screened for tuberculos is using intradermal tuberculin test. Mammalian and avian tuberculins were procured from Veterinary Research Institute, Lahore.

\section{Intradermal Tuberculin Test}

Intradermal tuberculin test was conducted according to the protocol described in the OIE.(2004) manual of standards for diagnostic tests and vaccines.

On each animal, two inches square of skin was shaved on the left side of the neck at two different points six inches apart. Skin fold was measured with the help of vernier caliper and the measurement was recorded as initial reading. The area was cleaned with alcohol swab and left to dry. $0.1 \mathrm{ml}$ (10000 IU) mammalian tuberculin was injected intradermally on the upper shaved area with the help of tuberculin syringe unless a bead was formed at the site of injection. On the lower shaved area, $0.1 \mathrm{ml}$ (10000 IU) avian tuberculin was injected intradermally to compare and for the indication of non specific reaction. Final readings were measured 72 hrs post injection using vernier caliper. Results were recorded by subtracting final readings from initial readings. Results were declared positive, negative or suspected on the following criteria as described by.

\section{Specific Reactions}

(a) An increase of thickness up to $2.9 \mathrm{~mm}$

$$
=\text { Negative }
$$

(b) An increase of thickness from 3 to $3.9 \mathrm{~mm} \quad=$ Suspected

(c) An increase of thickness of $4 \mathrm{~mm}$ or above= Positive

(d) Any oedema present regardless of measurement $=$ Positive

\section{Non Specific Reactions}

(a) If mammalian is not more than $4 \mathrm{~mm}$ greater than avian. = Negative

(b) If mammalian increase is greater than avian by 5 to $6.9 \mathrm{~mm}$. = Suspected

(c) If mammalian increase is greater than avian by $7 \mathrm{~mm}$ or above. = Positive

\section{Statistical Analysis}

Data for each animal species for each study year was pooled separately. Prevalence was expressed in the form of percentage. Proportions were compared by chi-square at level of significance $5 \%$ using computer software SPSS 16 for windows.

\section{Results and Discussion}

The study was conducted in 9021 cattle and 8580 buffalo from 2006 to 2010 at different livestock farms in Punjab for screening TB infection in cattle and buffalo. Intradermal tuberculin test detected 350 (13.63\%) cattle positive for TB out of 2567cattle examined during the year 2006-07 while 159 (6.19\%) cattle were found to be suspected for TB. In the year 2007-08 a total of 2489 cattle were examined and 285 (11.45\%) found positive for TB while $135(5.42 \%)$ were found to be suspected. A total of 1890 cattle were examined in the year 2008-09 out of which 
$197(10.42 \%)$ cattle were found to be positive for TB whereas 100 (5.29\%) cattle were found suspected. In the following year 2009-10, a total of 2075 cattle were examined out of which 225 (10.84\%) cattle were found to be positive for TB and 105 $(5.06 \%)$ cattle were found suspected for TB (Fig. I).

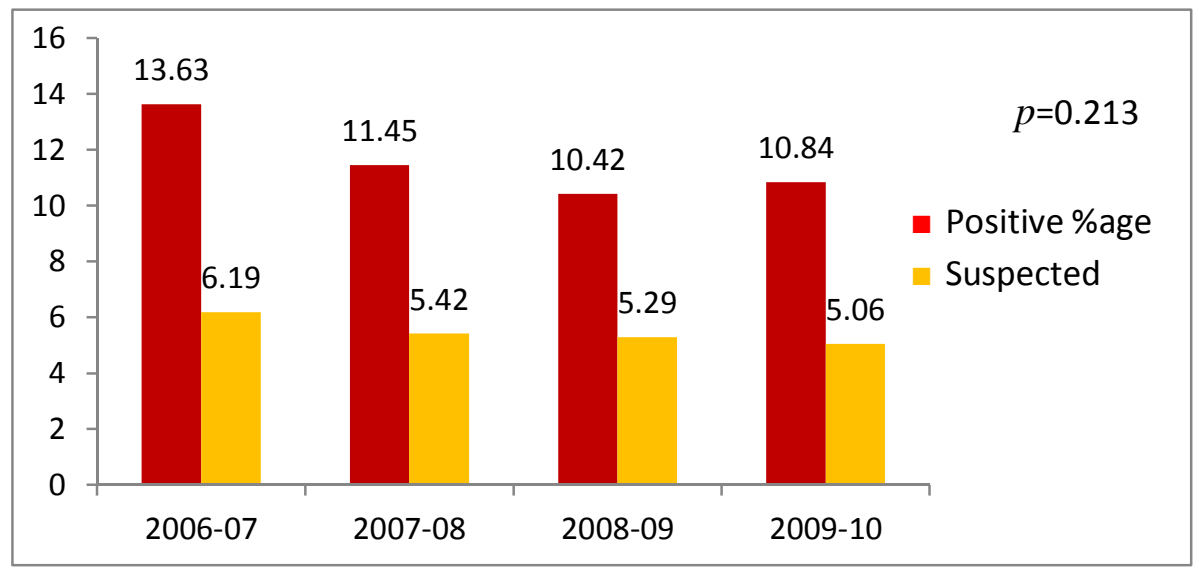

Fig. I. Comparison of Prevalence of TB from 2006-2010 in Cattle Population Using Chisquare Analysis with Level of Significance 5\%.

A total of 2372 buffalo were examined for TB using intradermal tuberculin test in the year 2006-07 and 378 (15.94\%) buffalo were recorded as positive while $176(7.41 \%)$ were suspected. In the year 2007-08 a total of 2132 buffalo were examined out of which $289(13.55 \%)$ were found positive for TB while 169 (7.92\%) were suspected. Buffalo examined for the year 2008-09 counted to be 2087 out of which $210(10.06 \%)$ were found positive for TB and 121 (5.79\%) were found to be suspected. In the year 2009-10, buffalo examined for TB counted to be 1989 out of which 150 (7.54\%) were positive and 102 $(5.12 \%)$ were suspected (Fig. II).

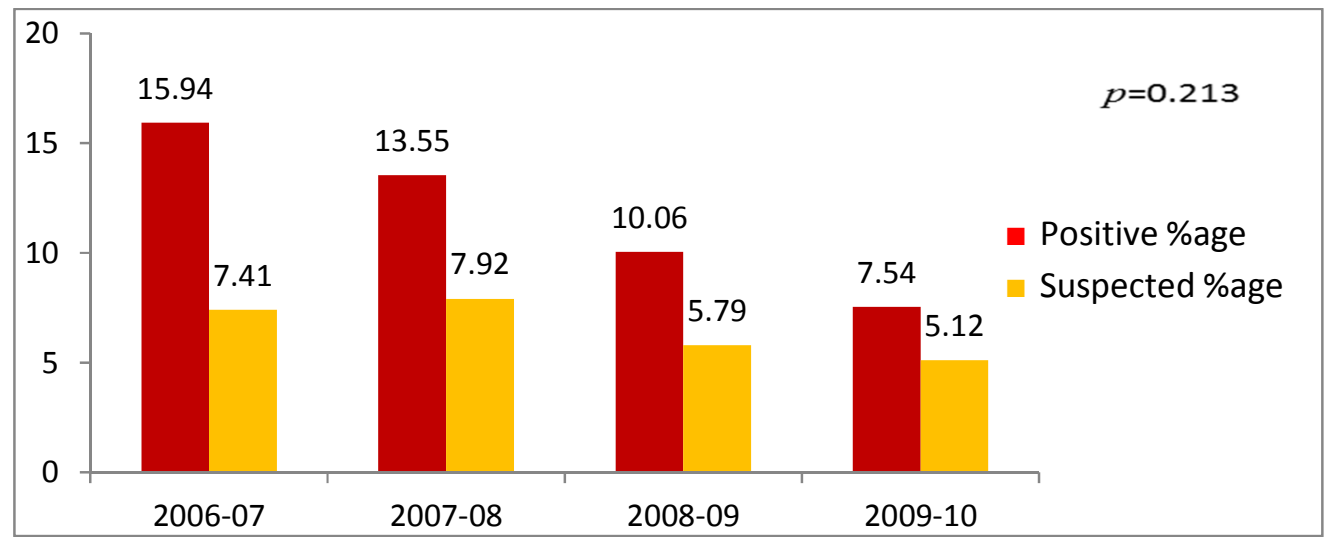

Fig. II. Comparison of Prevalence of TB from 2006-2010 in Buffalo Population Using Chisquare Analysis with Level of Significance 5\% 
A total of 17601 animals were screened for intradermal TB test from 2006-10. Out of the total animals tested, 1057 (11.71\%) cattle and 1027 (11.96\%) buffalo showed positive reaction to intradermal TB test (Table I). Statistical analysis showed that prevalence of TB was insignificantly different in both species and was more or less similar to reported by other workers. The prevalence of bovine TB in buffaloes was reported $4.37 \%$ by Akhtere $t$ a l., (1992), $1.7 \%$ by Ifrahim (2001), 5.48\% by Javed et al., (2006), 12.72 $\%$ by Khan and Khan (2007) and $10.6 \%$ by Khan et al., (2008) in different parts of the country. Whereas, Javed et al., (2011) reported $8 \%$ prevalence of tuberculos is in cattle.

Table I: Prevalence of Cattle and Buffalo for TB from 2006-10.

\begin{tabular}{|l|l|l|l|l|l|}
\hline Year & Species & positive & Positive\% & suspected & Suspected\% \\
\hline \multirow{3}{*}{$2006-10$} & Cattle & 1057 & 11.71 & 499 & 5.53 \\
\cline { 2 - 6 } & Buffalo & 1027 & 11.96 & 568 & 6.62 \\
\hline \multicolumn{2}{|r|}{ Total } & 2084 & 11.84 & 1067 & 6.06 \\
\hline
\end{tabular}

\section{References}

Akhter, S., Khan, M. I. \& Anjum, A. D. (1992). 'Comparative Delayed Cutaneous Hypersensitivity in Buffaloes and Cattle; Reaction to Tuberculin Purified Protein Derivatives,' Buffalo Journal, 8(1) 39-45.

Bonsu, O. A., Laing, E., Akanmori, B. D, Williams,D. J. L. \& wastling, J. M. (2000). "Prevalence of Tuberculosis in Cattle in the Dangme-West District of Ghana, Public Health Implications," Acta Tropica, 76, 9-14.

Collier, L., Bollows, A. \& Susman. (1998). 'Bacterial Infection, Microbiology and Microbial Infection,' 9(3) Arnold, London.

Cousins, D. V. (2001). "Mycobacterium Bovis Infection and Control in Domestic Livestock," Revue Scientifique et Technique, 20, 71-85.

Daborn, C. (1995). 'Tuberculosis in Human and Domestic Animals in the Developing World. Tuberculosis in Wild Life and Domestic Animals,' University of Otaga Press.

Javed, M. T., Irfan, M., Ali, I., Farooqi, F. A., Wasiq, M. \& Cagiola, M. (2011). "Risk Factors Identified Associated with Tuberculosis in Cattle at 11 Livestock Experiment Stations of Punjab Pakistan," Acta Tropica, 117(2) 10913.
Javed, M. T., Usman, M., Irfan, M. \& Cagiola, M. (2006). "A Study on Tuberculosis in Buffaloes: Some Epidemiological Aspects, along with Haematological and Serumprotein Changes", Veterinary Archives, 76(3) 193 206.

Khan, I. A. \& Khan, A. (2007). "Prevalence and Risk Factors of Bovine Tuberculosis in NiliRavi Buffaloes in the Punjab, Pakistan," Italian Journal of Animal Scinces, (6) 817-820.

Khan, I. A., Khan, A., Mubarak, A. \& Ali, S. (2008). "Factors Affecting Prevalence of Bovine Tuberculosis in Nili Ravi Buffaloes," Pakistan Veterinary Journal, 28(4) 155-158.

OIE. (2004). 'Manual of Diagnostic Tests and Vaccines for Terrestrial Animals,' Office Internationale des Epizooties (OIE), Paris, France. 